\title{
Distribution- and anchor-based methods to determine the minimally important difference on patient-reported outcome questionnaires in oncology: a structured review
}

Ahmad Ousmen ${ }^{1 *+}$, Célia Touraine ${ }^{2 \dagger}$, Nina Deliu $^{3}$, Francesco Cottone ${ }^{3}$, Franck Bonnetain ${ }^{1,4}$, Fabio Efficace ${ }^{3}$, Anne Brédart ${ }^{5,6}$, Caroline Mollevi ${ }^{2,4,7}$ and Amélie Anota ${ }^{1,4}$

\begin{abstract}
Background: Interpretation of differences or changes in patient-reported outcome scores should not only consider statistical significance, but also clinical relevance. Accordingly, accurate determination of the minimally important difference (MID) is crucial to assess the effectiveness of health care interventions, as well as for sample size calculation. Several methods have been proposed to determine the MID. Our aim was to review the statistical methods used to determine MID in patient-reported outcome (PRO) questionnaires in cancer patients, focusing on the distribution- and anchor-based approaches and to present the variability of criteria used as well as possible limitations.

Methods: We performed a systematic search using PubMed. We searched for all cancer studies related to MID determination on a PRO questionnaire. Two reviewers independently screened titles and abstracts to identify relevant articles. Data were extracted from eligible articles using a predefined data collection form. Discrepancies were resolved by discussion and the involvement of a third reviewer.

Results: Sixty-three articles were identified, of which 46 were retained for final analysis. Both distribution- and anchorbased approaches were used to assess the MID in 37 studies (80.4\%). Different time points were used to apply the distribution-based method and the most frequently reported distribution was the 0.5 standard deviation at baseline. A change in a PRO external scale $(N=13,30.2 \%)$ and performance status $(N=15,34.9 \%)$ were the most frequently used anchors. The stability of the MID over time was rarely investigated and only $28.2 \%$ of studies used at least 3 assessment timepoints. The robustness of anchor-based MID was questionable in $37.2 \%$ of the studies where the minimal number of patients by anchor category was less than 20 .
\end{abstract}

Conclusion: Efforts are needed to improve the quality of the methodology used for MID determination in PRO questionnaires used in oncology. In particular, increased attention to the sample size should be paid to guarantee reliable results. This could increase the use of these specific thresholds in future studies.

Keywords: Patient-reported outcomes, Minimally important difference, Anchor-based approach, Distribution-based approach

\footnotetext{
* Correspondence: ousmen.ahmad@hotmail.com

${ }^{\dagger}$ Ahmad Ousmen and Célia Touraine contributed equally to this work.

'Methodology and Quality of Life in Oncology Unit (INSERM UMR 1098),

University Hospital of Besançon, Besançon, France

Full list of author information is available at the end of the article
}

(c) The Author(s). 2018 Open Access This article is distributed under the terms of the Creative Commons Attribution 4.0 International License (http://creativecommons.org/licenses/by/4.0/), which permits unrestricted use, distribution, and reproduction in any medium, provided you give appropriate credit to the original author(s) and the source, provide a link to the Creative Commons license, and indicate if changes were made. The Creative Commons Public Domain Dedication waiver (http://creativecommons.org/publicdomain/zero/1.0/) applies to the data made available in this article, unless otherwise stated. 


\section{Introduction}

The use of patient-reported outcomes (PRO), including health-related quality of life (HRQOL), in cancer clinical trials has substantially increased over the years [1]. PROs are critical to fully understand overall treatment effectiveness and to establish the benefit of a given experimental drug over the standard of care in a particular cancer population [2,3]. Thus, assessment and analysis of PRO data must be carried out in compliance with a rigorous and appropriate methodology to ensure robust interpretation of the results [4].

The interpretation of PRO scores and their clinical importance is a major challenge, in terms of both clinically relevant score differences between two measurement times and two treatment arms [5]. A statistically significant result may not be clinically relevant, as it should also reflect changes or differences that are meaningful for the patient, i.e., they should take into account a minimally important difference (MID). The MID was defined by Jaeschke et al. as "the smallest change in an outcome that a patient would identify as important" [6]. Hence, the determination of the MID is crucial in order to assess the effectiveness of health care interventions, as well as for sample size calculation when HRQOL is the primary or co-primary endpoint in clinical trials.

Different methods have been proposed to determine the MID. These methods are generally grouped into two categories, namely anchor-based and distribution-based approaches $[7,8]$. The anchor-based approaches use an external indicator, called an "anchor", and differences can be determined either cross-sectionally (differences between clinically-defined groups at one time point) or longitudinally (change in the scores of a single group over time). The anchor can be either an objective measure (e.g., Karnofsky or ECOG performance status) or a subjective measure, generally reflecting the patient's point of view, which is of interest (for example, the patient rating of change). Distribution-based approaches are based on statistical criteria from the PRO scores. These approaches include fractions of the standard deviation (SD) of PRO scores, the effect size [9], and the standard error of measurement (SEM) [10] as estimates for the MID. Distribution-based approaches have the advantage of simplicity of use, since they do not require an external criterion. However, they produce similar MID results for both deterioration and improvement. This simplifies the interpretation but may be questionable, since a larger MID is often observed for deterioration than for improvement [11].

Some recommendations have been proposed regarding the best method to apply, depending on the design of the study. For instance, analysis must rely primarily on relevant patient-based and clinical anchors [12]. Moreover, both distribution- and anchor-based approaches remain the most commonly used methods to determine the MID [13]. However, robust and reliable determination of the MID remain challenging. In fact, due to the longitudinal design often used in MID analyses, a potential response shift effect may bias the results. The impact of the response shift effect on the longitudinal analysis of PRO is well established and has been widely studied [14]. However, studies investigating the impact of response shift effect on MID determination remain sparse [15]. Another important possible limitation of studies aiming to determine the MID is the sample size. Indeed, most studies aiming to explore the MID on a given PRO questionnaire use data from an existing cohort or randomized clinical trial. Thus, the volume of available data may not be sufficient to provide a reliable MID, in particular due to the number of possible categories for the anchor.

To date, longitudinal studies in oncology generally used the thresholds proposed by Osoba et al. in 1998 [5] for HRQOL for the interpretation of results, i.e. an MID of 5 or 10 points. However, these thresholds were obtained only on data collected with the European Organisation for Research and Treatment of Cancer (EORTC) QLQ-C30 cancer-specific questionnaire. A more recent meta-analysis proposed specific thresholds for each HRQOL scale of the EORTC QLQ-C30, and for each direction, i.e. improvement or deterioration [16]. Other studies proposed MID for specific cancer site questionnaires, such as the EORTC QLQ-BN20 for brain cancer [17], but few studies use these specific thresholds to interpret HRQOL results.

In this context, the objective of this structured review was to assess the most common practices used by the distribution and anchor-based approaches to determine the MID for PRO questionnaires in oncology, as well as the characteristics and the possible limitations relative to each approach.

\section{Methods}

\section{Search and selection strategy}

A systematic literature search was performed in the Pubmed database, of all articles published between January 2000 and May 2018. Eligible studies included original articles aiming to determine the MID of self-administered questionnaires in cancer, using distribution- and/or anchor based approaches. Only static questionnaires were considered, i.e. questionnaires that have a fixed number of questions answered by patient. It means, all patients will answer to the same questions in the same order. Accordingly, computer adaptive tests were not included in this review. Indeed, all studies using Item Response Theory models were not included since these types of models are very specific and results could not be directly comparable to studies using the 
summary score. All non-cancer studies were excluded as well as reviews and meta-analysis. The following search strategy was used:

(MCID OR MID OR MCIDs OR MIDs OR "minimal clinically important" OR "minimum clinically important" OR "minimally clinically important" OR "minimal important" OR "minimally important" OR "clinically meaningful" OR "meaningful change" OR "meaningful changes" OR "meaningful difference" OR "meaningful differences" OR "cutoff score" OR "cutoff scores") AND ("quality of life" OR QoL OR "patient-reported outcomes" OR "patient-reported outcome" OR PRO OR PROs OR HRQOL OR symptom OR symptoms) AND ("anchor-based" OR "distribution-based" OR anchored OR anchor) AND cancer AND ("2000/01/01"[Date MeSH]: "2018/05/31"[Date - MeSH])

\section{Data extraction}

Two reviewers (A.O., C.T.) independently screened first titles and abstracts and secondly full paper to identify relevant articles. Then, they independently extracted information from eligible studies using a predefined data extraction form (DEF). All discrepancies were resolved by mutual consensus. In case of disagreement, a third author (A.A.) was consulted to reach a final consensus.

This literature review was performed according to the Preferred Reporting Items for Systematic Reviews and Meta-Analysis (PRISMA) statement guidelines [18] and the following details were extracted:

- General items, namely, year of publication, number of patients, disease stage, type of study (randomized clinical trial, prospective cohort, or other), study location, international and multicenter study or not.

- Items regarding the PRO assessment, including the name of the PRO questionnaire for which the MID was determined, the time windows and number of measurement times considered for the MID determination.

- Items regarding the MID determination, including the term used for the MID designation (e.g., minimal important difference or minimal clinically important difference), name and number of PRO scales analyzed, level for statistical significance if appropriate, type (e.g. distribution or anchor based approach) and number of approaches used (1 or 2), and the design considered (cross-sectional or longitudinal). Regarding the anchor-based approach, information on the number and type of anchors used, the threshold considered to qualify the minimal important change, whether the correlation between the anchor and HRQOL/PRO scores was assessed, and the minimum number of patients included in each category of the anchor were collected. For the distribution-based approach, different criteria were extracted. Finally, whatever the method(s) used, we also recorded the recommendations proposed for the MID to be used in future studies, the limitations highlighted by the authors, and the potential risks of bias (for instance, missing data, bias in the selection population and bias in the statistical analysis (e.g. correlation between anchor and HRQOL score not assessed for longitudinal studies)).

\section{Data analysis}

A descriptive analysis of eligible publications was performed. Qualitative variables were summarized by tabulating frequency distribution and percentages and quantitative data by median and interquartile range (IQR). Analyses were performed using SAS version 9.3. (SAS Institute Inc., Cary, NC, USA).

\section{Results}

The initial search identified a total of 64 studies (Fig. 1). After screening of the title and abstract by the 2 reviewers, 15 studies were excluded because they were not relevant to the subject $(N=9)$, were not original papers $(N=3)$ or reported computer adaptive testing $(N=3)$. After reading the full text of the remaining 49 articles, three additional articles were excluded as they explored cut-off scores and not MID. Thus, a total of 46 studies were finally included in this review [13, 17, 19-62].

\section{Characteristics of the studies included}

The sample sizes of the studies included ranged from 50 to 3770 . The general results are presented in Table 1 . Among the 46 articles retained for analysis, 20 (43.5\%) enrolled patients with metastatic or advanced cancer, 5 (10.9\%) included patients with localized cancer, and 12

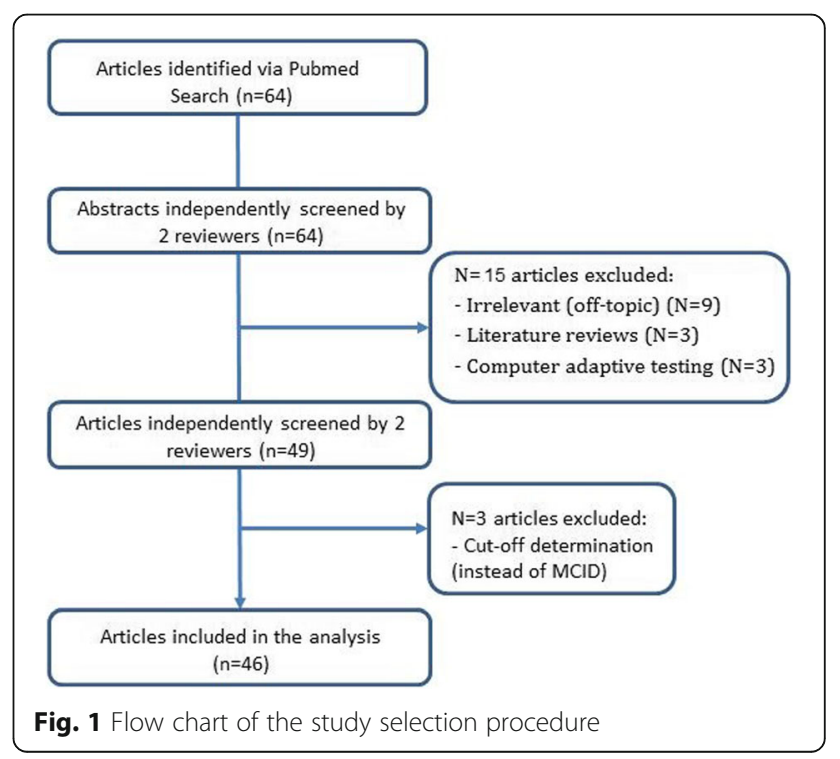


Table 1 General information for all studies selected $(N=46)$

\begin{tabular}{|c|c|c|}
\hline & Number & Percent \\
\hline \multicolumn{3}{|l|}{ Disease stage } \\
\hline Metastatic / Advanced & 20 & 43.5 \\
\hline Non metastatic / Local & 5 & 10.9 \\
\hline Both & 12 & 26.1 \\
\hline Unclear or not reported & 9 & 19.5 \\
\hline \multicolumn{3}{|l|}{ Type of study } \\
\hline Randomized clinical trials & 10 & 21.7 \\
\hline Prospective cohort study & 23 & 50 \\
\hline Other & 13 & 28.3 \\
\hline \multicolumn{3}{|l|}{ International study } \\
\hline Yes & 9 & 19.6 \\
\hline No & 37 & 80.4 \\
\hline \multicolumn{3}{|l|}{ Multicenter study } \\
\hline Yes & 22 & 47.8 \\
\hline No & 13 & 28.3 \\
\hline Unclear or not reported & 11 & 23.9 \\
\hline \multicolumn{3}{|l|}{ Questionnaires } \\
\hline EORTC QLQ-C30 & 10 & 21.7 \\
\hline EORTC QLQ-C15-PAL & 2 & 4.3 \\
\hline EORTC specific modules & 6 & 13.0 \\
\hline FACT-G & 1 & 2.2 \\
\hline Other FACT questionnaires & 13 & 21.7 \\
\hline Other multidimensional questionnaires & 8 & 17.4 \\
\hline Other specific PRO questionnaires & 13 & 28.2 \\
\hline
\end{tabular}

(26.1\%) included both. The majority of studies were prospective cohort studies $(N=23,50 \%)$ and 10 were randomized clinical trials (21.7\%). Eighteen studies (39\%) assessed the MID of an EORTC questionnaire, specifically, the EORTC QLQ-C30 questionnaire $(N=10,21.7 \%)$, the QLQ-C15-PAL $(N=2,4.3 \%)$ and EORTC specific modules, such as the EORTC QLQ-BN20 brain cancer module $(N=6,13 \%)$. Thirteen studies (26.1\%) evaluated the MID of a Functional Assessment of Cancer Therapy (FACT) questionnaire, of which 8 (61.5\%) used a FACT questionnaire specific to the cancer site, including the FACT-M for melanoma patients $(N=2,4.3 \%)$.

Other questionnaires assessed a specific PRO domain such as pain or fatigue. For example, 4 studies explored the MID of fatigue PRO questionnaires, such as the FACT-F $(N=1,2.3 \%)$, the Multidimensional Fatigue Inventory-20 (MFI-20) $(N=1,2.3 \%)$, the Multidimensional Fatigue Symptom Inventory-Short Form (MFSI-SF) $(N=1,2.3 \%)$ and 1 study (2.3\%) used three different instruments (the cancer fatigue scale (CFS), the Schwartz Cancer Fatigue Scale-revised (SCFS-r), and the fatigue symptom inventory (FSI)). Two other studies (4.4\%) addressed the MID of the Brief Pain Inventory or its short form. Finally, 5 studies (10.9\%) assessed the MID of generic questionnaires for cancer patients, for example the EuroQoL EQ-5D $(N=3,6.5 \%)$.

\section{Statistical analysis of the MID}

General results regarding the MID determination are presented in Table 2. Several terminologies were used to identify the MID. The MID was the most used acronym t with 29 studies (63\%), and referring to "Minimally important difference" $(N=16,34.8 \%)$ or "Minimal important difference" ( $N=13,28.2 \%)$. The second used term was the MCID referring to "Minimal clinically important difference" in 16 studies (34.8\%), to "Minimum clinically important difference" in 2 studies (4.3\%) and to "Minimal clinical important difference" in one study (2.2\%). The last used term was the MIC referring to "Minimal important change" in only one study (2.2\%).

Three studies (6.5\%) used only the distribution-based approach, 6 studies (13.1\%) used only the anchor-based approach, and 37 studies (80.4\%) used both. Concerning the number of assessment times, 2 studies (4.4\%) used only one measurement time for the determination of the MID, 31 studies (67.4\%) used two measurement times and 13 studies $(28.2 \%)$ used at least three measurement times. Only one study explored the impact of the occurrence of the response shift effect on the MID determination over time. The time interval between two assessment times varied from 2 days $(N=1,2.5 \%)$ to more than 1 year $(N=5,12.5 \%)$. For most of the studies, the time interval between two assessment was between 1 and 6 months $(N=27,58.7 \%)$. Floor and ceiling effects are studied in 7 studies (15.2\%). For 4 studies (57.1\%), the range of floor and ceiling effects is $<15 \%$. For only 2 studies $(28.6 \%)$, the range was $\geq 15 \%$ and not reported in one study (14.3\%).

\section{Distribution-based approach}

Results of distribution- and anchor-based approaches are presented in Table 3. A total of 40 studies (87\%) used distribution-based approaches. The reported criteria (fraction of SD or SEM) were extracted: at baseline, after follow-up and between two measurement times. The most commonly used distribution was the $0.5 \mathrm{SD}$ at baseline $(N=36,90 \%)$ followed by the SEM at baseline $(N=31,77.5 \%)$. Twenty-five studies (62.5\%) reported the $0.3 \mathrm{SD}$ at baseline and 12 studies (30\%) used the 0.2 $\mathrm{SD}$ at baseline. Among the other reported criteria, the 0.3 or $0.5 \mathrm{SD}$ at follow-up was reported by 14 studies (35\%) and the 0.3 or $0.5 \mathrm{SD}$ of a change by respectively $8(20 \%)$ and 7 studies (17.5\%).

\section{Anchor-based approach}

Forty-three studies (93.5\%) used the anchor-based approach to estimate the MID. Among them, 39 studies 
Table 2 General results regarding the minimally important difference (MID) determination $(N=46)$

\begin{tabular}{|c|c|c|}
\hline & Number & Percent \\
\hline \multicolumn{3}{|l|}{ Approach used for MID determination } \\
\hline Distribution-based only & 3 & 6.5 \\
\hline Anchor-based only & 6 & 13.1 \\
\hline Both distribution- and anchor-based & 37 & 80.4 \\
\hline \multicolumn{3}{|l|}{ Term used to design the MID } \\
\hline MID, referring to: & 29 & 63 \\
\hline Minimally important difference & 16 & 34.8 \\
\hline Minimal important difference & 13 & 28.2 \\
\hline MCID, referring to: & 19 & 41.3 \\
\hline Minimal clinically important difference & 16 & 34.8 \\
\hline Minimum clinically important difference & 2 & 4.3 \\
\hline Minimal clinical important difference & 1 & 2.2 \\
\hline MIC, referring to: & 1 & 2.2 \\
\hline Minimal important change & 1 & 2.2 \\
\hline \multicolumn{3}{|l|}{ Number of assessment timepoints } \\
\hline 1 & 2 & 4.4 \\
\hline 2 & 31 & 67.4 \\
\hline 3 & 6 & 13 \\
\hline$\geq 4$ & 7 & 15.2 \\
\hline \multicolumn{3}{|l|}{ Time interval between the assessment times } \\
\hline 2 days & 1 & 2.2 \\
\hline 1 month & 7 & 15.2 \\
\hline $3-6$ months & 6 & 13 \\
\hline 1 year & 2 & 4.4 \\
\hline Based on clinical relevance & 3 & 6.5 \\
\hline Multiple with a maximum interval of 6 months & 14 & 30.4 \\
\hline Multiple with a maximum interval > 1 year & 5 & 10.9 \\
\hline Multiple intervals based on clinical relevance & 2 & 4.4 \\
\hline \multicolumn{3}{|l|}{ Floor and ceiling effects studied } \\
\hline Yes & 7 & 15.2 \\
\hline Floor and ceiling effects detected $(<15 \%)$ & 2 & 28.6 \\
\hline Floor and ceiling effects no detected ( $<15 \%)$ & 4 & 57.1 \\
\hline Not reported & 1 & 14.3 \\
\hline No & 39 & 84.8 \\
\hline \multicolumn{3}{|l|}{ Recommendations for futures studies } \\
\hline Yes & 16 & 34.8 \\
\hline No & 23 & 50 \\
\hline Unclear & 7 & 15.2 \\
\hline \multicolumn{3}{|l|}{ Limitations highlighted by authors } \\
\hline Yes & 42 & 91.3 \\
\hline No & 4 & 8.7 \\
\hline
\end{tabular}

Table 2 General results regarding the minimally important difference (MID) determination ( $N=46)$ (Continued)

\begin{tabular}{lll}
\hline & Number & Percent \\
\hline Possible risk of bias & & \\
Missing data on the HRQOL/PRO measures & 16 & 40 \\
Bias in the selection of the population & 17 & 42.5 \\
Bias in the statistical analysis & 5 & 10.9 \\
\hline
\end{tabular}

(92.9\%) used a longitudinal design regarding the anchor while only 3 studies (7.1\%) used a cross-sectional design. The correlation between the anchor and the PRO scores was assessed in 32 studies (74.4\%). The most used threshold to detect a moderate correlation between anchor and HRQOL scores was 0.3 in 15 studies (46.9\%). Every dimension with a correlation greater than this threshold $(|\mathrm{r}| \geq 0.3)$ was retained for the MID determination. For 15 studies (46.9\%), the correlation has been calculated but there was no specified threshold for the retained scales that have been used in the MID determination. The minimal number of patients analyzed by category of anchor was less than 20 in 16 studies (37.2\%). For instance, 13 and 7 patients were used for one category of the anchor to qualify deterioration and improvement respectively in two studies.

Twenty-three studies (53.5\%) used only one anchor, while the other studies used from $2(18.6 \%)$ to more than 5 anchors (13.9\%). The median number of anchors used was 1 (IQR 1-3). Various anchors were used to assess the MID. Some were subjective, i.e. patient centered and reflecting the patient's perception of change or HRQOL, while others were more objective, reflecting clinical or biological measures or the physician's assessment of change. A total of 28 studies (65.1\%) used at least one patient-centered anchor and 15 studies (34.9\%) exclusively used some objective anchors (Table 4).

Regarding patient-centered anchors, 9 studies (20.9\%) used the patient's overall rating of change in HRQOL, or a specific domain, while 18 studies (41.9\%) used an anchor derived from a PRO questionnaire. This could either be a PRO scale from the same questionnaire on which the MID was determined $(N=8,18.6 \%)$, or an external questionnaire $(N=13,30.2 \%)$. For example, the global HRQOL dimension or overall QoL item of the EORTC QLQ-C30 or QLQ-C15-PAL questionnaire was used as an anchor in 5 studies (11.6\%), while the MID was determined on other dimensions of the EORTC QLQ-C30 or QLQ-C15PAL. An external item or scale derived from another questionnaire was also used as an anchor in 13 studies (30.2\%). For example, a visual analogue scale of fatigue was used in one study as an anchor to determine the MID on the FACT-Fatigue questionnaire. The fatigue dimension of the EORTC QLQ-C30 was also used as an anchor in one study to determine the MID on the MFSI-SF questionnaire. 
Table 3 Results of distribution and anchor based approaches $(N=46)$

\begin{tabular}{|c|c|c|}
\hline & Number & Percent \\
\hline \multicolumn{3}{|l|}{ Distribution-based approach $(N=40)$} \\
\hline \multicolumn{3}{|l|}{ Distribution-reported } \\
\hline 0.2 SD at baseline & 12 & 30 \\
\hline 0.3 SD at baseline & 25 & 62.5 \\
\hline $0.5 \mathrm{SD}$ at baseline & 36 & 90 \\
\hline SEM at baseline & 31 & 77.5 \\
\hline $0.2 \mathrm{SD}$ at follow-up & 7 & 17.5 \\
\hline $0.3 \mathrm{SD}$ at follow-up & 14 & 35 \\
\hline $0.5 \mathrm{SD}$ at follow-up & 14 & 35 \\
\hline SEM at follow-up & 13 & 32.5 \\
\hline $0.2 \mathrm{SD}$ of change & 2 & 5 \\
\hline $0.3 \mathrm{SD}$ of change & 8 & 20 \\
\hline $0.5 \mathrm{SD}$ of change & 7 & 17.5 \\
\hline SEM of change & 5 & 12.5 \\
\hline \multicolumn{3}{|l|}{ Anchor-based approach $(N=43)$} \\
\hline \multicolumn{3}{|l|}{ Study design } \\
\hline Cross-sectional & 3 & 7.1 \\
\hline Longitudinal design & 39 & 92.9 \\
\hline \multicolumn{3}{|l|}{ Number of anchors } \\
\hline 1 & 23 & 53.5 \\
\hline 2 & 8 & 18.6 \\
\hline 3 & 3 & 7 \\
\hline 4 & 3 & 7 \\
\hline$\geq 5$ & 6 & 13.9 \\
\hline \multicolumn{3}{|l|}{ Anchors } \\
\hline Overall rating of change & 9 & 20.93 \\
\hline Anchor derived from an external questionnaire & 13 & 30.2 \\
\hline $\begin{array}{l}\text { Anchor derived from one dimension of the } \\
\text { questionnaire studied }\end{array}$ & 8 & 18.6 \\
\hline Performance status & 15 & 34.9 \\
\hline MMSE & 1 & 2.3 \\
\hline Weight loss & 1 & 2.3 \\
\hline Other & 10 & 23.3 \\
\hline \multicolumn{3}{|l|}{$\begin{array}{l}\text { Correlation checked between anchor } \\
\text { and the studied questionnaire }\end{array}$} \\
\hline Yes & 32 & 76.2 \\
\hline No & 9 & 21.4 \\
\hline \multicolumn{3}{|l|}{ Criteria used to detect a moderate correlation $(N=32)$} \\
\hline$\geq 0.3$ & 15 & 46.9 \\
\hline$\geq 0.4$ & 1 & 3.1 \\
\hline$\geq 0.5$ & 1 & 3.1 \\
\hline Not reported & 15 & 46.9 \\
\hline
\end{tabular}

Table 3 Results of distribution and anchor based approaches $(N=46)$ (Continued)

\begin{tabular}{lll}
\hline & Number & Percent \\
\hline Minimum N by anchor category & 16 & 37.2 \\
$\leq 20$ & 18 & 41.9 \\
$>20$ & 9 & 20.9 \\
$\quad$ Not reported & & \\
\hline $\begin{array}{l}\text { SD standard deviation, SEM standard error of measurement, MMSE mini mental } \\
\text { state examination }\end{array}$ &
\end{tabular}

Regarding clinical anchors, the performance status (either Karnofsky or ECOG) was used in 15 studies (34.9\%). Weight loss and the Mini-Mental State Examination (MMSE) score were both used in one study (2.3\%).

Studies using the same anchor did not necessarily use the same threshold to qualify the minimal change for the anchor. For example, among the 5 studies using the global HRQOL dimension or its items individually as an anchor, 2 studies used a 10-point difference in the global score as a minimal change and 3 studies used only one item of the overall QoL scale by considering a change of two units $(N=2)$ or one unit $(N=1)$ as the minimal change. When these single items are standardized on a 0 to 100 scale, a change of one unit corresponds to a change of 16.7 points and a change of two units corresponds to a change of 33.3 points. Regarding studies using physician-reported performance status as an anchor, they generally used a 10 point difference for the Karnofsky index and change of one category for the ECOG as a clinically relevant change.

To complement these results, we summarized the information collected for the main questionnaires used in our review, namely the EORTC QLQ-C30 and the FACT questionnaire in the Additional file 1: Table S1. Among the 23 studies using either the EORTC QLQ-C30 or the FACT questionnaire, 18 (78.3\%) used both distribution and anchor-based method to determine the MID. Among the 21 studies that used the anchor-based approach to determine the MID for either EORTC QLQ-C30 or FACT questionnaires, 4 studies (19\%) determined the MID without distinction between improvement and deterioration.

Sixteen studies (34.8\%) proposed recommendations for MID for use in futures studies. In the majority of studies $(N=42,91.3 \%)$, some limitations were reported by the authors. Regarding the possible risk of bias, 16 studies (43.2\%) were impacted by the occurrence of missing data on the PRO measures; in 17 studies (47.2\%), the selection of the population could be subject to a risk of bias, and for 5 studies (19.2\%) there was a risk of bias due to the statistical analysis.

\section{Discussion}

The objective of this structured review was to assess the most common practices used by the distribution and 
anchor based approaches to determine the MID for PRO questionnaires in oncology, and to present the variability of criteria used as well as possible limitations relative to each approach. We limited our research to year 2000 because we think a review of papers published since almost two decades would be reasonable and enough to conduct this review. Eligible studies included original articles aiming to determine the MID of self-administered questionnaires in cancer, using distribution- and/or anchor based approaches.

Using both the distribution and anchor-based approaches, as was the case in the majority of studies (80\%), makes it possible to compare results for consistency, to highlight the strengths and weaknesses of each method, and to retain the most appropriate MID value or range to apply in further studies [12].

For the distribution-based approach, several criteria were reported at different assessment times. As already highlighted in previous reviews [63], the most frequently reported criterion was $0.5 \mathrm{SD}$ at baseline, reported in $90 \%$ of studies using the distribution-based method. Despite the simplicity and the widespread use of this approach in the determination of the MID, no distinction can be made between improvement and deterioration.

Regarding the anchor-based approach, most studies used a longitudinal design (92.9\%). Various anchors were applied, and were either patient- or physician-reported measures, as well as clinical or biological measures with clinical relevance. The most commonly used anchor was a PRO score or item, derived from the questionnaire of interest or from another questionnaire (41.9\%). When this anchor was derived from the questionnaire for which the MID was being determined, then the MID on the corresponding dimension could not be assessed. This is the case for example when the overall HRQOL score is used as an anchor to estimate the MID on the QLQ-C30. Moreover, this requires to fix a threshold to qualify the clinically meaningful change on one dimension of the studied questionnaire. Finally, the choice of this kind of anchor could be questionable since the property of external criteria for the anchor is not entirely respected.

Another frequently used patient-centered anchor (used in $20.9 \%$ of the studies using the anchor-based approach) is the patient's overall rating of change. This anchor reflects the patient's perception of change, but it needs to be planned in the design of the study.

A large proportion of studies also used physician-reported measures such as performance status or MMSE score. These anchors could be considered as objective evaluations of the patient's health status. However, they may not be appropriate for the assessment of the MID on all HRQOL dimensions. Given that performance status reflects the physical condition of the patient, it is generally correlated to the physical dimensions of HRQOL. Similarly, the MMSE is mostly correlated with the cognitive dimension of HRQOL. Thus, these anchors preclude assessment of the MID for more physiological or emotional dimensions of HRQOL [17]. This also means that several anchors are needed to accurately assess the MID and to check the robustness and complementarity of the results obtained using different anchors [12]. In our review, half the studies (53.5\%) using an anchor-based approach used only one anchor. For the majority of the studies, the correlation between the anchor and scores of the studied questionnaire has been checked. The threshold of 0.3 was the most used criteria to detect a moderate correlation. On the other side, an important frequency of studies $(46.9 \%)$ from those who checked correlation did not reported the criteria to identify a moderate correlation. Generally, checking correlation is important to know to what extent the anchor used is linked to HRQOL measure. Hence, the correlation between the anchor and the PRO scores must be assessed and only dimensions that are significantly correlated with the anchor (correlation coefficient $|\mathrm{r}|>0.3$ ) should be analyzed. In this review, $76.2 \%$ of the studies using an anchor-based approach verified this correlation.

The majority of the studies with a longitudinal design (58.7\%) used a time interval between 1 and 6 months between two consecutive assessments. However, wide variation was observed between studies. A standard period remains to be determined, and further research is warranted to determine a suitable time window. This point is particularly important when the patient's overall rating of change is used as an anchor, since long periods between assessments could induce a recall bias.

The majority of studies (71.7\%) used one or two measurement times to determine the MID, but the stability over time was rarely investigated. For example, a change in PRO score of 5 points could be insignificant for the patients at the time of diagnosis, whereas it might be highly relevant after surgery. Therefore, it is strongly recommended to assess the MID with more than two measurement times [62]. This change in the patients' perception of HRQOL change over time could reflect the occurrence of a response shift effect [64]. In our review, only one study investigated the impact of the occurrence of response shift on the MID determination using the patient's overall rating of change as the anchor. However, the response shift effect could differentially impact on the results of the MID depending on the anchor used. Future studies are warranted to investigate this possible risk of bias and take it into account in the MID determination [15].

Several terminologies were used to identify the MID. However, using a standardized term and acronym referring to the MID should be investigated in future studies to avoid variability in terminology and to obtain more 
Table 4 Information including number of patients included and analyzed and anchor used for each study selected ( $N=46)$

\begin{tabular}{|c|c|c|c|c|}
\hline Reference & $\begin{array}{l}\text { Number of } \\
\text { patients included }\end{array}$ & $\begin{array}{l}\text { Number of patients } \\
\text { included in the analysis } \\
\text { (range for multiple analyses) }\end{array}$ & $\begin{array}{l}\text { Questionnaires on which the } \\
\text { MID was determined }\end{array}$ & Anchor \\
\hline $\begin{array}{l}\text { Askew, R.L. } \\
\text { (2009) [19] }\end{array}$ & 273 & 163 & FACT-M & Performance status \\
\hline $\begin{array}{l}\text { Bédard, G. } \\
\text { (2014) [21] }\end{array}$ & 369 & 367 to 369 & EORTC QLQ-C30 & $\begin{array}{l}\text { Global HRQOL dimension } \\
\text { of the QLQ-C30 }\end{array}$ \\
\hline $\begin{array}{l}\text { Bédard, G. } \\
\text { (2016) [22] }\end{array}$ & 276 & 276 & EORTC QLQ-C15-PAL & $\begin{array}{l}\text { Global HRQOL dimension } \\
\text { of the QLQ-C15 PAL }\end{array}$ \\
\hline $\begin{array}{l}\text { Bédard, G. } \\
\text { (2016) [22] }\end{array}$ & 421 & 197 to 276 & $\begin{array}{l}\text { EDMONTON SYMPTOM } \\
\text { ASSESSMENT SYSTEM (ESAS) }\end{array}$ & Well-being dimension of the ESAS \\
\hline $\begin{array}{l}\text { Bharmal, M. } \\
\text { (2017) [23] }\end{array}$ & 88 & 70 & FACT-M & Percentage change in tumor size \\
\hline $\begin{array}{l}\text { Binenbaum, } \mathrm{T} \text {. } \\
(2014)[24]\end{array}$ & 1011 & 329 to 631 & $\begin{array}{l}\text { UW-QOLQ, EORTC } \\
\text { QLQ-C30, QLQ-H\&N35 }\end{array}$ & No anchor used \\
\hline $\begin{array}{l}\text { Cella, D. } \\
\text { (2009) [26] }\end{array}$ & 809 & 809 & FACT-P & Performance status \\
\hline $\begin{array}{l}\text { Cella, D. } \\
\text { (2002) [13] }\end{array}$ & 50 & 50 to 2402 & FACT-AN & Performance status; hemoglobin level \\
\hline $\begin{array}{l}\text { Cella, D. } \\
(2002)[25]\end{array}$ & 599 & 573 & FACT-L & $\begin{array}{l}\text { Best overall response to treatment, } \\
\text { time to disease progression }\end{array}$ \\
\hline Chan, A. (2018) [27] & 257 & 201 & MFSI-SF & Fatigue dimension of the QLQ-C30 \\
\hline $\begin{array}{l}\text { Cheung, Y.T. } \\
\text { (2014) [28] }\end{array}$ & 330 & 220 & FACT-Cog & Cognitive dimension of the QLQ-C30 \\
\hline $\begin{array}{l}\text { Den Oudsten, B.L. } \\
\text { (2013) [29] }\end{array}$ & 606 & 355 & WHOQOL-100 & QoL of the WHOQoL \\
\hline $\begin{array}{l}\text { Eton, D.T. } \\
\text { (2007) [32] }\end{array}$ & 92 & 91 & $\begin{array}{l}\text { FACT-G, FACT-Lung } \\
\text { Symptom Index-12 }\end{array}$ & Performance status \\
\hline $\begin{array}{l}\text { Eton, D.T. } \\
\text { (2006) [30] }\end{array}$ & 209 & 209 & FACT-BRM & $\begin{array}{l}\text { Clinical distinct groups using } \\
\text { performance status }\end{array}$ \\
\hline $\begin{array}{l}\text { Eton, D.T. } \\
\text { (2004) [31] }\end{array}$ & 771 & 128 to 643 & FACT-B & $\begin{array}{l}\text { Performance status, physician } \\
\text { assessment of current pain, and } \\
\text { response to treatment }\end{array}$ \\
\hline $\begin{array}{l}\text { Granger, C.L. } \\
(2015)[34]\end{array}$ & 69 & 69 & $\begin{array}{l}\text { Physical Activity Scale For } \\
\text { The Elderly (PASE) }\end{array}$ & No anchor used \\
\hline $\begin{array}{l}\text { Granger, C.L. } \\
(2015)[33]\end{array}$ & 56 & 63 to 66 & 6-Minute Walk Distance & $\begin{array}{l}\text { Physical functioning dimension } \\
\text { of the QLQ-C30 }\end{array}$ \\
\hline $\begin{array}{l}\text { Hong, F. } \\
\text { (2013) [35] }\end{array}$ & 765 & 627 & EORTC QLQ-C30 & Patient's rating of change \\
\hline $\begin{array}{l}\text { Hui, D. } \\
\text { (2016) [36] }\end{array}$ & 796 & 792 to 795 & $\begin{array}{l}\text { Edmonton Symptom Assessment } \\
\text { System (ESAS) }\end{array}$ & Patient's rating of change \\
\hline $\begin{array}{l}\text { Jayadevappa, R. } \\
\text { (2012) [37] }\end{array}$ & 602 & 528 & $\begin{array}{l}\text { SF-36, UCLA Prostate } \\
\text { Cancer Index (PCI) }\end{array}$ & $\begin{array}{l}\text { A patient-reported physical } \\
\text { signs/symptoms (more tired or } \\
\text { worn out than usual) }\end{array}$ \\
\hline $\begin{array}{l}\text { Kemmler, G. } \\
(2010)[38]\end{array}$ & 187 & 160 & EORTC QLQ-C30 & Patient's rating of change \\
\hline $\begin{array}{l}\text { Lemieux, J. } \\
(2007)[39]\end{array}$ & 235 & 133 & $\begin{array}{l}\text { EORTC QLQ-C30, POMS, } \\
\text { MAC, IES, PAIS, PAIN }\end{array}$ & No anchor used \\
\hline Liu, H. (2015) [40] & 2440 & $\leq 246$ & 2 single-item questions & Patient's rating of change \\
\hline $\begin{array}{l}\text { Maringwa, J.T } \\
\text { (2011) [41] }\end{array}$ & 941 & 420 to 572 & EORTC QLQ-C30, QLQ-BN20 & Performance status; MMSE \\
\hline $\begin{array}{l}\text { Maringwa, J.T } \\
\text { (2011) [41] }\end{array}$ & 812 & 410 to 519 & EORTC QLQ-C30 & $\begin{array}{l}\text { Performance status; } \\
\text { weight change }\end{array}$ \\
\hline $\begin{array}{l}\text { Mathias, S.D. } \\
\text { (2011) [42] }\end{array}$ & 2049 & 1564 & $\begin{array}{l}\text { Brief Pain Inventory-Short } \\
\text { Form (BPI-SF) }\end{array}$ & $\begin{array}{l}\text { BPI-SF current pain and EQ-5D } \\
\text { index score }\end{array}$ \\
\hline
\end{tabular}


Table 4 Information including number of patients included and analyzed and anchor used for each study selected ( $N=46)$ (Continued)

\begin{tabular}{|c|c|c|c|c|}
\hline Reference & $\begin{array}{l}\text { Number of } \\
\text { patients included }\end{array}$ & $\begin{array}{l}\text { Number of patients } \\
\text { included in the analysis } \\
\text { (range for multiple analyses) }\end{array}$ & $\begin{array}{l}\text { Questionnaires on which the } \\
\text { MID was determined }\end{array}$ & Anchor \\
\hline $\begin{array}{l}\text { Mouysset, J.L. } \\
\text { (2016) [43] }\end{array}$ & 1262 & 510 & FACT-F & VAS of fatigue \\
\hline $\begin{array}{l}\text { Ousmen, A. } \\
\text { (2016) [62] }\end{array}$ & 381 & 74 to 260 & EORTC QLQ-C30; QLQ-BR23 & Patient's rating of change \\
\hline $\begin{array}{l}\text { Pickard, A.S. } \\
\text { (2007) [44] }\end{array}$ & 534 & 534 & EQ-5D & Performance status \\
\hline $\begin{array}{l}\text { Purcell, A. } \\
\text { (2010) [45] }\end{array}$ & 210 & 157 to 199 & $\mathrm{MFI}-20$ & $\begin{array}{l}\text { VAS of the EQ-5D; performance } \\
\text { status; treatment impact on fatigue }\end{array}$ \\
\hline $\begin{array}{l}\text { Raman, S. } \\
\text { (2016) [46] }\end{array}$ & 298 & 201 to 204 & EORTC QLQ-BM22, QLQ-C15-PAL & $\begin{array}{l}\text { Global HRQOL dimension of } \\
\text { the QLQ-C15 PAL }\end{array}$ \\
\hline $\begin{array}{l}\text { Raman, S. } \\
\text { (2018) [47] }\end{array}$ & 850 & 360 to 375 & EORTC QLQ-C30, BPI & $\begin{array}{l}\text { Global HRQOL dimension of } \\
\text { the QLQ-C30 }\end{array}$ \\
\hline $\begin{array}{l}\text { Sagberg, L.M. } \\
\text { (2014) [48] }\end{array}$ & 173 & 142 to 164 & EQ-5D $3 L$ & Performance status \\
\hline $\begin{array}{l}\text { Shun, S.C } \\
(2007)[49]\end{array}$ & 243 & 148 & 3 fatigue instruments & Patient's rating of change \\
\hline $\begin{array}{l}\text { Skolarus, T.A. } \\
\text { (2015) [50] }\end{array}$ & 1201 & 1201 & EPIC-26 & $\begin{array}{l}\text { Item from the service satisfaction } \\
\text { scale for cancer care scale }\end{array}$ \\
\hline $\begin{array}{l}\text { Steel, J. L. } \\
\text { (2006) [51] }\end{array}$ & 158 & 158 & FACT-HEP & $\begin{array}{l}\text { Alpha-fetoprotein, alkaline } \\
\text { phosphate and hemoglobin } \\
\text { levels, survival }\end{array}$ \\
\hline $\begin{array}{l}\text { Tamminga, S.J. } \\
\text { (2014) [52] }\end{array}$ & 53 & 43 & Work Limitations Questionnaire (WLQ) & Patient's rating of change \\
\hline $\begin{array}{l}\text { Tsiplova, K. } \\
\text { (2016) [53] }\end{array}$ & 3770 & 3765 & EQ-5D & Global health question \\
\hline $\begin{array}{l}\text { Tuomi, L. } \\
\text { (2016) [54] }\end{array}$ & 126 & 119 & $\begin{array}{l}\text { Swedish self-evaluation of } \\
\text { communication experiences } \\
\text { after laryngeal cancer (S-SECEL) }\end{array}$ & $\begin{array}{l}\text { Acceptability of speech in } \\
\text { a social context }\end{array}$ \\
\hline $\begin{array}{l}\text { Wong, E. } \\
\text { (2015) [55] }\end{array}$ & 99 & 77 to 99 & EORTC QLQ-BN20 & $\begin{array}{l}\text { Item } 30 \text { of the QLQ-C30 or } \\
15 \text { of QLQ-C15 PAL }\end{array}$ \\
\hline $\begin{array}{l}\text { Wong, K. } \\
\text { (2013) [56] }\end{array}$ & 414 & 153 to 233 & Brief Pain Inventory (BPI) & Pain score of the BPI \\
\hline $\begin{array}{l}\text { Wright, P. } \\
\text { (2008) [57] }\end{array}$ & 276 & 187 & Social Difficulty Inventory & $\begin{array}{l}\text { Social functioning dimension } \\
\text { of the QLQ-C30 }\end{array}$ \\
\hline $\begin{array}{l}\text { Yost, K.J. } \\
(2005)[58]\end{array}$ & 200 & 144 to 164 & FACT-BRM & $\begin{array}{l}\text { Patient's rating of change; } \\
\text { performance status }\end{array}$ \\
\hline $\begin{array}{l}\text { Yost, K.J. } \\
(2005)[58]\end{array}$ & 60 & 60 to 568 & FACT-C & Performance status \\
\hline $\begin{array}{l}\text { Yost, K.J. } \\
(2011)[59]\end{array}$ & 101 & 88 to 101 & PROMIS-cancer scales & $\begin{array}{l}\text { Patient's rating of change; } \\
\text { performance status; } \\
21 \text { other anchors }\end{array}$ \\
\hline $\begin{array}{l}\text { Zeng, L. } \\
\text { (2012) [61] }\end{array}$ & 400 & 88 to 93 & EORTC QLQ-C30, QLQ-BM22 & Performance status \\
\hline
\end{tabular}

accurately the maximum number of articles needed for future analysis.

A frequent limitation was the small sample size in the anchor categories. If the number of patients in each category of anchor is not sufficient, then the resulting MID cannot be reliable and the robustness in this case is thus questionable. Only one study determined the sample size specifically for the MID analysis. This sample size calculation must be systematically performed for MID determination, even if the analysis is not the primary objective of the study, for example when data from a randomized clinical trial are used. Calculating an appropriate sample size per category will ensure the robustness of the results. Furthermore, the occurrence of missing data can also bias the MID analysis. Therefore, it is also important 
to determine the profile of missing data, and consider imputing missing data using the appropriate method.

Using only one electronic database (PubMed searches) was the main limitation of this work. Unfortunately, due to lack of resource, we could not use other databases to perform this review. A risk of bias could thus be observed since other interesting papers may not be captured in this database. Hopefully, a manual research conducted to the same papers obtained via our algorithm in Pubmed.

This review must be expanded in future studies to address all methods that have been used to determine the MID either if they are including or not including in distribution-based or anchor-based methods (i.e. minimal detectable change, Receiver operating characteristic (ROC) curve, Item Response Theory, etc.).

In light of these results, greater attention should be paid to the methodology in future studies investigating the MID of a given PRO questionnaire, in order to ensure reliable results. This will also make it possible to use the MID for sample size determination when designing clinical trials with HRQOL or PRO as a primary endpoint, as well as for facilitating interpretation of the results. In the context of clinical trials in oncology, the MID is rarely used to interpret results in a clinically meaningful way. In a recent review of phase III trials in non-small cell lung cancer including a PRO endpoint, only $20 \%$ of studies interpreted the results in light of the MID [65]. The time-to-HRQOL-deterioration is a recently proposed method to analyze longitudinal HRQOL data [66]. One advantage of this method is to incorporate the MID in the definition of the event to qualify the deterioration. This guarantees the clinical significance of the results, but the choice of the MID is crucial since it has a direct impact on the results of the analysis.

\section{Conclusions}

Further research is mandatory to improve the quality of the methodology used to determine the MID in HRQOL questionnaires used in oncology. In particular, the choice of an appropriate anchor(s) when using the anchor-based approach, or appropriate criteria when using the distribution-based approach is essential. The sample size should also be taken into account to produce reliable results. This could increase the use of these specific thresholds in future studies.

\section{Additional file}

Additional file 1: Table S1. Information about Minimal important difference determination of the most used questionnaires (EORTC QLQC 30 and FACT) (DOCX $32 \mathrm{~kb}$ )

\section{Abbreviations}

EORTC: European organization for research and treatment of cancer; FACT: Functional assessment of cancer therapy; HRQOL: Health-related quality of life; MID: Minimally important difference; MMSE: Mini-Mental State Examination; PRO: Patient-reported outcome; SD: Standard deviation; SEM: Standard error of measurement

\section{Acknowledgments}

The authors thank Fiona Ecarnot (EA3920, University Hospital Besancon, University of Franche-Comté, Besançon, France) for editorial assistance. We acknowledge also the Professor Woronoff-Lemsi (University Hospital Besancon, University of Franche-Comté, Besançon, France) for supporting this work.

\section{Funding}

This work was supported by a grant from the "Institut National du Cancer (INCA_10846)". The study sponsor had no role in the conception, the design of the study, the data acquisition and analysis or in the manuscript preparation.

\section{Availability of data and materials}

Please contact author for data requests.

\section{Authors' contributions}

$\mathrm{AO}$ and $\mathrm{CT}$ contributed equally in the statistical analyses and the writing of the manuscript. AA coordinated the study and participated in writing the manuscript. All authors: ND, FC, FB, FE, AB, CM, and AA read and approved the final manuscript.

\section{Ethics approval and consent to participate}

Not applicable

\section{Consent for publication}

Not applicable

\section{Competing interests}

None of the authors have competing interests in relation to this manuscript.

\section{Publisher's Note}

Springer Nature remains neutral with regard to jurisdictional claims in published maps and institutional affiliations.

\section{Author details}

${ }^{1}$ Methodology and Quality of Life in Oncology Unit (INSERM UMR 1098), University Hospital of Besançon, Besançon, France. ${ }^{2}$ Montpellier Cancer Institute (ICM) - Val d'Aurelle, University of Montpellier, Montpellier, France. ${ }^{3}$ Italian Group for Adult Hematologic Diseases (GIMEMA), Data Center and Health Outcomes Research Unit, Rome, Italy. ${ }^{4}$ French National Platform Quality of Life and Cancer, Besançon, France. ${ }^{5}$ Institut Curie, Supportive Care Department, Psycho-Oncology Unit, Paris, France. ${ }^{6}$ University Paris Descartes, Psychopathology and health process laboratory EA 4057,

Boulogne-Billancourt, France. ${ }^{7}$ IRCM, University of Montpellier, ICM, INSERM, Montpellier, France.

Received: 4 July 2018 Accepted: 28 November 2018

Published online: 11 December 2018

References

1. Efficace F, Fayers P, Pusic A, Cemal Y, Yanagawa J, Jacobs M, la Sala A, Cafaro V, Whale K, Rees J, et al. Quality of patient-reported outcome reporting across cancer randomized controlled trials according to the CONSORT patient-reported outcome extension: a pooled analysis of 557 trials. Cancer. 2015;121:3335-42.

2. Beitz J, Gnecco C, Justice R. Quality-of-life end points in cancer clinical trials: the U.S Food and Drug Administration perspective. J Natl Cancer Inst Monogr. 1996:7-9.

3. Vodicka E, Kim K, Devine EB, Gnanasakthy A, Scoggins JF, Patrick DL. Inclusion of patient-reported outcome measures in registered clinical trials: evidence from ClinicalTrials.gov (2007-2013). Contemp Clin Trials. 2015:43:1-9.

4. Bonnetain F, Fiteni F, Efficace F, Anota A. Statistical challenges in the analysis of health-related quality of life in Cancer clinical trials. J Clin Oncol. 2016;34:1953-6. 
5. Osoba D, Rodrigues G, Myles J, Zee B, Pater J. Interpreting the significance of changes in health-related quality-of-life scores. J Clin Oncol. 1998;16:139-44.

6. Jaeschke R, Singer J, Guyatt $\mathrm{GH}$. Measurement of health status. Ascertaining the minimal clinically important difference. Control Clin Trials. 1989;10:407-15

7. Crosby RD, Kolotkin RL, Williams GR. Defining clinically meaningful change in health-related quality of life. J Clin Epidemiol. 2003;56:395-407.

8. Lydick E, Epstein RS. Interpretation of quality of life changes. Qual Life Res. 1993:2:221-6.

9. Kazis LE, Anderson JJ, Meenan RF. Effect sizes for interpreting changes in health status. Med Care. 1989;27:S178-89.

10. Wyrwich KW, Tierney WM, Wolinsky FD. Further evidence supporting an SEM-based criterion for identifying meaningful intra-individual changes in health-related quality of life. J Clin Epidemiol. 1999;52:861-73.

11. Cella D, Hahn EA, Dineen K. Meaningful change in cancer-specific quality of life scores: differences between improvement and worsening. Qual Life Res. 2002;11:207-21.

12. Revicki D, Hays RD, Cella D, Sloan J. Recommended methods for determining responsiveness and minimally important differences for patient-reported outcomes. J Clin Epidemiol. 2008;61:102-9.

13. Cella D, Eton DT, Lai JS, Peterman AH, Merkel DE. Combining anchor and distribution-based methods to derive minimal clinically important differences on the functional assessment of Cancer therapy (FACT) anemia and fatigue scales. J Pain Symptom Manag. 2002;24:547-61.

14. Hamidou Z, Dabakuyo TS, Bonnetain F. Impact of response shift on longitudinal quality-of-life assessment in cancer clinical trials. Expert Rev Pharmacoecon Outcomes Res. 2011;11:549-59.

15. Kvam AK, Wisloff F, Fayers PM. Minimal important differences and response shift in health-related quality of life; a longitudinal study in patients with multiple myeloma. Health Qual Life Outcomes. 2010;8:79.

16. Cocks K, King MT, Velikova G, de Castro GJ, Martyn St-James M, Fayers PM, Brown JM. Evidence-based guidelines for interpreting change scores for the European organisation for the research and treatment of Cancer quality of life questionnaire Core 30. Eur J Cancer. 2012;48:1713-21.

17. Maringwa J, Quinten C, King M, Ringash J, Osoba D, Coens C, Martinelli F, Reeve BB, Gotay C, Greimel E, et al. Minimal clinically meaningful differences for the EORTC QLQ-C30 and EORTC QLQ-BN20 scales in brain cancer patients. Ann Oncol. 2011;22:2107-12.

18. Moher D, Liberati A, Tetzlaff J, Altman DG, Group P. Preferred reporting items for systematic reviews and meta-analyses: the PRISMA statement. PLoS Med. 2009;6:e1000097.

19. Askew RL, Xing Y, Palmer JL, Cella D, Moye LA, Cormier JN. Evaluating minimal important differences for the FACT-melanoma quality of life questionnaire. Value Health. 2009;12:1144-50.

20. Bedard G, Zeng L, Zhang L, Lauzon N, Holden L, Tsao M, Danjoux C, Barnes E, Sahgal A, Poon M, Chow E. Minimal clinically important differences in the Edmonton symptom assessment system in patients with advanced cancer. $J$ Pain Symptom Manag. 2013:46:192-200.

21. Bedard G, Zeng L, Zhang L, Lauzon N, Holden L, Tsao M, Danjoux C, Barnes E, Sahgal A, Poon M, Chow E. Minimal important differences in the EORTC QLQ-C30 in patients with advanced cancer. Asia Pac J Clin Oncol. 2014;10: 109-17.

22. Bedard G, Zeng L, Zhang L, Lauzon N, Holden L, Tsao M, Danjoux C, Barnes E, Sahgal A, Poon M, et al. Minimal important differences in the EORTC QLQ-C15-PAL to determine meaningful change in palliative advanced cancer patients. Asia Pac J Clin Oncol. 2016;12:e38-46.

23. Bharmal M, Fofana F, Barbosa CD, Williams $P$, Mahnke $L$, Marrel A, Schlichting M. Psychometric properties of the FACT-M questionnaire in patients with Merkel cell carcinoma. Health Qual Life Outcomes. 2017; 15:247.

24. Binenbaum Y, Amit M, Billan S, Cohen JT, Gil Z. Minimal clinically important differences in quality of life scores of oral cavity and oropharynx cancer patients. Ann Surg Oncol. 2014;21:2773-81.

25. Cella D, Eton DT, Fairclough DL, Bonomi P, Heyes AE, Silberman C, Wolf MK, Johnson $\mathrm{DH}$. What is a clinically meaningful change on the functional assessment of Cancer therapy-lung (FACT-L) questionnaire? Results from eastern cooperative oncology group (ECOG) study 5592. J Clin Epidemiol. 2002;55:285-95

26. Cella D, Nichol MB, Eton D, Nelson JB, Mulani P. Estimating clinically meaningful changes for the functional assessment of Cancer therapy-- prostate: results from a clinical trial of patients with metastatic hormonerefractory prostate cancer. Value Health. 2009;12:124-9.

27. Chan A, Yo TE, Wang XJ, Ng T, Chae JW, Yeo HL, Shwe M, Gan YX. Minimal clinically important difference of the multidimensional fatigue symptom inventory-short form (MFSI-SF) for fatigue worsening in Asian breast Cancer patients. J Pain Symptom Manag. 2018;55:992-7 e992.

28. Cheung YT, Foo YL, Shwe M, Tan YP, Fan G, Yong WS, Madhukumar P, Ooi WS, Chay WY, Dent RA, et al. Minimal clinically important difference (MCID) for the functional assessment of cancer therapy: cognitive function (FACTcog) in breast cancer patients. J Clin Epidemiol. 2014;67:811-20.

29. Den Oudsten BL, Zijlstra WP, De Vries J. The minimal clinical important difference in the World Health Organization quality of life instrument--100 Support Care Cancer. 2013;21:1295-301.

30. Eton DT, Cella D, Bacik J, Motzer RJ. A brief symptom index for advanced renal cell carcinoma. Health Qual Life Outcomes. 2006;4:68.

31. Eton DT, Cella D, Yost KJ, Yount SE, Peterman AH, Neuberg DS, Sledge GW, Wood WC. A combination of distribution- and anchor-based approaches determined minimally important differences (MIDs) for four endpoints in a breast cancer scale. J Clin Epidemiol. 2004:57:898-910.

32. Eton DT, Cella D, Yount SE, Davis KM. Validation of the functional assessment of cancer therapy--lung symptom index-12 (FLSI-12). Lung Cancer. 2007;57:339-47.

33. Granger $\mathrm{CL}$, Holland $\mathrm{AE}$, Gordon IR, Denehy L. Minimal important difference of the 6-minute walk distance in lung cancer. Chron Respir Dis. 2015;12:146-54.

34. Granger CL, Parry SM, Denehy L. The self-reported physical activity scale for the elderly (PASE) is a valid and clinically applicable measure in lung cancer. Support Care Cancer. 2015;23:3211-8.

35. Hong F, Bosco JL, Bush N, Berry DL. Patient self-appraisal of change and minimal clinically important difference on the European organization for the research and treatment of cancer quality of life questionnaire core 30 before and during cancer therapy. BMC Cancer. 2013;13:165.

36. Hui D, Shamieh O, Paiva CE, Khamash O, Perez-Cruz PE, Kwon JH, Muckaden MA, Park M, Arthur J, Bruera E. Minimal clinically important difference in the physical, emotional, and Total symptom distress scores of the Edmonton symptom assessment system. J Pain Symptom Manag. 2016;51:262-9.

37. Jayadevappa R, Malkowicz SB, Wittink M, Wein AJ, Chhatre S. Comparison of distribution- and anchor-based approaches to infer changes in health-related quality of life of prostate cancer survivors. Health Serv Res. 2012;47:1902-25.

38. Kemmler G, Zabernigg A, Gattringer K, Rumpold G, Giesinger J, SpernerUnterweger B, Holzner B. A new approach to combining clinical relevance and statistical significance for evaluation of quality of life changes in the individual patient. J Clin Epidemiol. 2010;63:171-9.

39. Lemieux J, Beaton DE, Hogg-Johnson S, Bordeleau LJ, Goodwin PJ. Three methods for minimally important difference: no relationship was found with the net proportion of patients improving. J Clin Epidemiol. 2007;60:448-55.

40. Liu H, Tan AD, Qin R, Sargent DJ, Grothey A, Buckner JC, Schaefer PL, Sloan JA. Comparing and validating simple measures of patient-reported peripheral neuropathy for oncology clinical trials: NCCTG N0897 (Alliance) a pooled analysis of 2440 patients. SOJ Anesthesiol Pain Manag. 2015;2.

41. Maringwa JT, Quinten C, King M, Ringash J, Osoba D, Coens C, Martinelli F, Vercauteren J, Cleeland CS, Flechtner $\mathrm{H}$, et al. Minimal important differences for interpreting health-related quality of life scores from the EORTC QLQC30 in lung cancer patients participating in randomized controlled trials. Support Care Cancer. 2011:19:1753-60.

42. Mathias SD, Crosby RD, Qian Y, Jiang Q, Dansey R, Chung K. Estimating minimally important differences for the worst pain rating of the brief pain inventory-short form. J Support Oncol. 2011;9:72-8.

43. Mouysset $\mathrm{J}$, Freier $B$, van den Bosch J, Levache CB, Bols A, Tessen HW, Belton L, Bohac GC, Terwey JH, Tonini G. Hemoglobin levels and quality of life in patients with symptomatic chemotherapy-induced anemia: the eAQUA study. Cancer Manag Res. 2016:8:1-10.

44. Pickard AS, Neary MP, Cella D. Estimation of minimally important differences in EQ-5D utility and VAS scores in cancer. Health Qual Life Outcomes. 2007:5:70

45. Purcell A, Fleming J, Bennett S, Burmeister B, Haines T. Determining the minimal clinically important difference criteria for the multidimensional fatigue inventory in a radiotherapy population. Support Care Cancer. 2010;18:307-15

46. Raman S, Ding K, Chow E, Meyer RM, Nabid A, Chabot P, Coulombe G, Ahmed S, Kuk J, Dar AR, et al. Minimal clinically important differences in the EORTC 
QLQ-BM22 and EORTC QLQ-C15-PAL modules in patients with bone metastases undergoing palliative radiotherapy. Qual Life Res. 2016;25:2535-41.

47. Raman S, Ding K, Chow E, Meyer RM, van der Linden YM, Roos D, Hartsell WF, Hoskin P, Wu JSY, Nabid A, et al. Minimal clinically important differences in the EORTC QLQ-C30 and brief pain inventory in patients undergoing re-irradiation for painful bone metastases. Qual Life Res. 2018;27:1089-98.

48. Sagberg LM, Jakola AS, Solheim O. Quality of life assessed with EQ-5D in patients undergoing glioma surgery: what is the responsiveness and minimal clinically important difference? Qual Life Res. 2014;23:1427-34.

49. Shun SC, Beck SL, Pett MA, Richardson SJ. Assessing responsiveness of cancer-related fatigue instruments: distribution-based and individual anchor-based methods. Oncologist. 2007;12:495-504

50. Skolarus TA, Dunn RL, Sanda MG, Chang P, Greenfield TK, Litwin MS, Wei JT, Consortium P. Minimally important difference for the expanded prostate Cancer index composite short form. Urology. 2015;85:101-5.

51. Steel JL, Eton DT, Cella D, Olek MC, Carr BI. Clinically meaningful changes in health-related quality of life in patients diagnosed with hepatobiliary carcinoma. Ann Oncol. 2006;17:304-12.

52. Tamminga SJ, Verbeek JH, Frings-Dresen MH, De Boer AG. Measurement properties of the work limitations questionnaire were sufficient among cancer survivors. Qual Life Res. 2014;23:515-25.

53. Tsiplova K, Pullenayegum E, Cooke T, Xie F. EQ-5D-derived health utilities and minimally important differences for chronic health conditions: 2011 Commonwealth Fund survey of sicker adults in Canada. Qual Life Res. 2016; 25:3009-16

54. Tuomi L, Johansson M, Andrell P, Finizia C. Interpretation of the Swedish self evaluation of communication experiences after laryngeal cancer: cutoff levels and minimum clinically important differences. Head Neck. 2016;38:689-95.

55. Wong E, Zhang L, Kerba M, Arnalot PF, Danielson B, Tsao M, Bedard G, Thavarajah N, Cheon P, Danjoux C, et al. Minimal clinically important differences in the EORTC QLQ-BN20 in patients with brain metastases. Support Care Cancer. 2015;23:2731-7.

56. Wong K, Zeng L, Zhang L, Bedard G, Wong E, Tsao M, Barnes E, Danjoux C, Sahgal $A$, Holden $L$, et al. Minimal clinically important differences in the brief pain inventory in patients with bone metastases. Support Care Cancer. 2013:21:1893-9.

57. Wright P, Marshall L, Smith AB, Velikova G, Selby P. Measurement and interpretation of social distress using the social difficulties inventory (SDI). Eur J Cancer. 2008;44:1529-35.

58. Yost KJ, Cella D, Chawla A, Holmgren E, Eton DT, Ayanian JZ, West DW. Minimally important differences were estimated for the functional assessment of Cancer therapy-colorectal (FACT-C) instrument using a combination of distribution- and anchor-based approaches. J Clin Epidemiol. 2005;58:1241-51.

59. Yost KJ, Eton DT, Garcia SF, Cella D. Minimally important differences were estimated for six patient-reported outcomes measurement information system-Cancer scales in advanced-stage cancer patients. I Clin Epidemiol. 2011;64:507-16.

60. Yost KJ, Sorensen MV, Hahn EA, Glendenning GA, Gnanasakthy A, Cella D. Using multiple anchor- and distribution-based estimates to evaluate clinically meaningful change on the functional assessment of Cancer therapy-biologic response modifiers (FACT-BRM) instrument. Value Health. 2005;8:117-27.

61. Zeng L, Chow E, Zhang L, Tseng LM, Hou MF, Fairchild A, Vassiliou V, Jesus-Garcia R, Alm El-Din MA, Kumar A, et al. An international prospective study establishing minimal clinically important differences in the EORTC QLQ-BM22 and QLQ-C30 in cancer patients with bone metastases. Support Care Cancer. 2012;20:3307-13.

62. Ousmen A, Conroy T, Guillemin F, Velten M, Jolly D, Mercier M, Causeret S, Cuisenier J, Graesslin O, Hamidou Z, et al. Impact of the occurrence of a response shift on the determination of the minimal important difference in a health-related quality of life score over time. Health Qual Life Outcomes. 2016;14:167.

63. Norman GR, Sloan JA, Wyrwich KW. Interpretation of changes in healthrelated quality of life: the remarkable universality of half a standard deviation. Med Care. 2003;41:582-92.

64. Sprangers MA, Schwartz CE. Integrating response shift into health-related quality of life research: a theoretical model. Soc Sci Med. 1999:48:1507-15.
65. Fiteni F, Anota A, Westeel V, Bonnetain F. Methodology of healthrelated quality of life analysis in phase III advanced non-small-cell lung cancer clinical trials: a critical review. BMC Cancer. 2016;16:122.

66. Bonnetain F, Dahan L, Maillard E, Ychou M, Mitry E, Hammel P, Legoux $J$, Rougier P, Bedenne L, Seitz JF. Time until definitive quality of life score deterioration as a means of longitudinal analysis for treatment trials in patients with metastatic pancreatic adenocarcinoma. Eur $\mathrm{J}$ Cancer. 2010;46:2753-62.
Ready to submit your research? Choose BMC and benefit from:

- fast, convenient online submission

- thorough peer review by experienced researchers in your field

- rapid publication on acceptance

- support for research data, including large and complex data types

- gold Open Access which fosters wider collaboration and increased citations

- maximum visibility for your research: over $100 \mathrm{M}$ website views per year

At BMC, research is always in progress.

Learn more biomedcentral.com/submissions 